\title{
EDITORIAL
}

\section{When Education Faces the COVID-19 Pandemic}

\author{
Editorial Office of Science Insights Education Frontiers
}

$\mathbf{I}^{\mathrm{N}}$

$\mathrm{N}$ the face of COVID-19, countries around the world have taken proactive measures accordingly. While actively controlling the epidemic, most countries are also actively exploring how to maintain normal social functioning and provide basic education activities within our ability. With the spread of COVID-19 worldwide, many countries have adopted online education and teaching activities accordingly.

In order to provide a better reference for online education activities in various countries, the Editorial Office of Science Insights Education Frontiers organizes and publishes special issue to report the situation of education during the pandemic, as well as the practices and experiences of online education activities. Meanwhile, theoretical exploration and evidence-based studies are conducted on this brand-new educational activity.

In this special issue, we include not only the overall consideration of school education during the pandemic, but also evidence-based studies on the effects of education measures. There are teaching strategies adopted by countries in the face of the COVID-19 pandemic, as well as psychological comfort and intervention for students. There are not only the teaching methods of elementary and middle schools, but also the technology support to the regional teaching activities. There are reports on the status of online education where they are suffering from the pandemic, as well as measures to deal with the pandemic when the school resumes learning after the COVID-19 has gradually been controlled.

The editorial office of the journal hopes that through the publication of this special issue, it will provide certain experience and necessary reference for countries in the world to carry out education during and after the epidemic. What we particularly need to acknowledge hereto is that some of the manuscripts presented in this issue are not "academic research" in a strict sense. We believe that at such an urgent moment, academic standards should give way to realistic needs to a certain extent. In addition, after this special issue, we will continue to solicit and publish outstanding manuscripts about COVID-19 and its impact in the field of education. 